\title{
In vivo deuterated water labeling allows tumor visualization via deuterium magnetic resonance spectroscopic imaging of cholesterol
}

Julian C. Assmann ${ }^{1 \dagger}$, Jeffrey R. Brender ${ }^{2 \dagger}$, Don E. Farthing ${ }^{1}$, Keita Saito ${ }^{2}$, Shun Kishimoto ${ }^{2}$, Kathrynne A. Warrick ${ }^{1}$, Natella Maglakelidze ${ }^{1}$, Daniel R. Crooks ${ }^{3}$, Hellmut Merkle ${ }^{4}$, Ronald E. Gress $^{1}$, Murali C. Krishna ${ }^{2}$, Nataliya P. Buxbaum ${ }^{1^{*}}$

${ }^{1}$ Experimental Transplantation and Immunotherapy Branch, National Cancer Institute, National Institutes of Health, Bethesda, Maryland, USA

${ }^{2}$ Radiation Biology Branch, Center for Cancer Research, National Cancer Institute, National Institutes of Health, Bethesda, Maryland, USA

${ }^{3}$ Urologic Oncology Branch, Center for Cancer Research, National Cancer Institute, National Institutes of Health, Bethesda, Maryland, USA

${ }^{4}$ Laboratory for Functional and Molecular Imaging, National Institute of Neurological Disorders and Stroke, National Institutes of Health, Bethesda, Maryland, USA

†contributed equally

"Corresponding author:

Nataliya P. Buxbaum, M.D., Experimental Transplantation and Immunotherapy Branch, National Cancer Institute, Bethesda, Maryland, USA, Email: nbuxbaum@mail.nih.gov, Phone: (240) 7606157

\begin{abstract}
Water is an essential component of many biochemical reactions. Deuterated water $\left(D_{2} O\right)$ has been used to study cell kinetics, protein synthesis, and metabolism. We hypothesized that rapidly proliferating cancer cells would become preferentially labeled with deuterium due to high metabolic activity, thus allowing imaging of biosynthetically labeled metabolites within tumors in vivo. We initiated systemic $\mathrm{D}_{2} \mathrm{O}$ labeling in two established tumor xenograft models, HT-29 and MiaPaCa-2 and imaged mice by deuterium magnetic resonance spectroscopic imaging (dMRSI). After 14 days of tumor growth and 7 days of in vivo labeling, a clear contrast was demonstrated between the xenograft and the contralateral control limb in both models. The origin of the contrast was traced to an aliphatic peak at $1.8 \mathrm{ppm}$, which was identified by ex vivo NMR analysis to originate from cholesterol and cholesterol esters. Cholesterol is important for tumor cell proliferation, signaling, and malignant transformation, while current methods to monitor cholesterol synthesis and accumulation are limited. This deuterated water labeling-imaging approach could complement current cancer imaging techniques, allowing not only imaging of uptake but also synthesis of cholesterol to elucidate effects on tumor cholesterol metabolism in vivo.
\end{abstract}


bioRxiv preprint doi: https://doi.org/10.1101/809327; this version posted May 28, 2020. The copyright holder for this preprint (which was not certified by peer review) is the author/funder. All rights reserved. No reuse allowed without permission.

\section{Introduction}

Imaging is an essential tool for cancer diagnosis, staging, and surveillance. Positron emission tomography (PET) and computer tomography (CT) scans are commonly used in this setting. They provide clinically valuable information that can guide therapeutic decisions (1-3). Radioactive tracers, such as ${ }^{18}$ fluorodeoxyglucose (FDG), in combination with CT take advantage of unique features of cancer cells such as their highly proliferative and glycolytic nature, allowing identification of small tumors that are not detectable by anatomical imaging alone (4). Such detection can result in clinically meaningful outcomes for patients, as surgical or medical interventions can be undertaken at lower tumor burden, i.e. prior to local growth and/or metastasis.

While PET tracers can probe multiple pathways, the signal is insensitive to the exact chemical fate of the tracer and the information gained is therefore primarily limited to uptake and retention. As evidence accumulates that alterations in metabolism are critical for tumor survival and progression, alternatives to PET-CT are currently being developed that can track such alterations. This includes hyperpolarized ${ }^{13} \mathrm{C}-\mathrm{MRI}$, a technique that uses dynamic nuclear polarization (DNP) to facilitate detection of ${ }^{13} \mathrm{C}$-labeled substrates (e.g. ${ }^{13} \mathrm{C}$-pyruvate) (5).

We hypothesized that, instead of using a labeled radiotracer, we would be able to label tumors in vivo biosynthetically by providing deuterated water $\left(\mathrm{D}_{2} \mathrm{O}\right)$ as a labeled substrate systemically and for relatively short periods to exploit the differential proliferation and metabolic rates of cancer cells and normal tissues. By definition, malignant cells exhibit rapid growth and frequent cell division. To sustain these high rates of proliferation, tumor cells must generate new cellular biomass $(6,7)$. During biosynthesis, (deuterated) water can be used as a substrate for enzymatic reactions in multiple pathways, leading to the formation of stable carbon-deuterium bonds that are not exchangeable with hydrogen, thus allowing in vivo labeling of proliferating cells via simple oral administration of deuterated water (8-10). This principle has formed the basis for the decades-long use of $\mathrm{D}_{2} \mathrm{O}$ to study cell cycle kinetics in both patients and animal models with virtually no adverse effects reported at low to moderate concentrations, up to $30 \% \mathrm{v} / \mathrm{v}$ in animal studies (11-13). These studies used mass spectrometry to measure cell division rates of cells during a specified labeling period and subsequently extracted from tissues or blood for the analysis. Following extraction, deuterium incorporation into newly synthesized DNA strands was quantified to estimate how many new cells were formed during the in vivo labeling period.

In vivo imaging offers several advantages by limiting invasiveness and improving coverage compared to ex vivo analyses of tissue biopsies. Deuterium magnetic resonance spectroscopic imaging (dMRSI) is an emerging technique to measure metabolic changes in vivo by MRI. dMRSI takes advantage of the rapid relaxation of the deuterium nucleus to enable faster cycling of scans, thereby regaining some of the reduced sensitivity from its low-gamma spin $(14,15)$. Here, we present a novel imaging approach using in vivo $\mathrm{D}_{2} \mathrm{O}$ labeling followed by dMRSI for the visualization of tumors in two xenograft mouse models. We recently used this technique to visualize target organs of graft-versus-host disease infiltrated by alloreactive $\mathrm{T}$ cells, which share certain features with tumor cells, i.e. rapid proliferation and glycolytic metabolism (13). Using this deuterium administration protocol with tumor-bearing mice, we quantitatively show by mass spectrometric analysis that tumor xenografts undergo a concentration-dependent enrichment of deuterium into the DNA base deoxyadenosine (dA). Furthermore, by combining deuterium labeling with dMRSI, we quantitatively showed cholesterol accumulation in two independent tumor models, demonstrating the ability of this technique to provide unique metabolic information. This relatively easy to implement, non-radioactive imaging method could provide a useful addition to the imaging arsenal for cancer research. 


\section{Methods}

Mice

Female athymic nude $\left(\right.$ Foxn $\left.1^{\text {nu }}\right)$ mice aged 10 - 15 weeks were supplied by the Frederick Cancer Research Center (Frederick, MD, USA). Mice were kept under a 12h/12h light-dark cycle with ad libitum access to food and water. All animal procedures were approved by the $\mathrm{NCl}$ Institutional Animal Use and Care Committee.

\section{Cells}

The human colorectal adenocarcinoma cell line HT-29 was purchased from ATCC (HTB38 ) and the identity was confirmed using a panel of microsatellite markers (IDEXX Laboratories). HT-29 cells were cultured in RPMI 1640 supplemented with $10 \%$ fetal bovine serum, $100 \mathrm{U} / \mathrm{ml}$ penicillin, $100 \mu \mathrm{g} / \mathrm{ml}$ streptomycin and incubated at $5 \% \mathrm{CO}_{2}$ and $37{ }^{\circ} \mathrm{C}$. On the day of tumor injection, HT-29 cells were spun down at $1000 \mathrm{rpm}$ for $5 \mathrm{~min}$, resuspended in PBS and $1 \times 10^{6}$ cultured cells were injected subcutaneously into the right proximal hind limb of the mouse as published previously (16). The contralateral hind limb of each mouse did not receive a tumor cell injection and served as an intra-individual control. Similarly, the human pancreatic cancer cell line MiaPaCa-2 (CRL-1420) was cultured as described above and $3 \times 10^{6}$ cells were injected subcutaneously into the right hind limb.

\section{Deuterium labeling}

The dMRSI studies were performed per the experimental schema described in Fig. 2 either 7 or 14 days after tumor cell implantation. For these imaging studies, a $\mathrm{D}_{2} \mathrm{O}$ level of $\sim 8 \%$ in total body water (TBW) was targeted. The mice initially received two bolus injections $(35 \mathrm{ml} / \mathrm{kg}$ body weight) containing $\mathrm{NaCl}(0.9 \%, w / v)$ in $\mathrm{D}_{2} \mathrm{O}(100 \%$, Cambridge Isotope Laboratories) $24 \mathrm{~h}$ apart, each bolus increasing the TBW enrichment by $\sim 4 \%$. Thereafter, the mice were provided drinking water containing $16 \%(\mathrm{v} / \mathrm{v}) \mathrm{D}_{2} \mathrm{O}\left(70 \% \mathrm{D}_{2} \mathrm{O}\right.$, Cambridge Isotope Laboratories, diluted with sterile ultra-pure water, Quality Biological) until imaging was performed (8). Administration of 16\% (v/v) $D_{2} \mathrm{O}$ was necessary to maintain $8 \% \mathrm{D}_{2} \mathrm{O}$ in TBW taking into account the $30-40 \%$ loss of $\mathrm{D}_{2} \mathrm{O}$ due to respiration and excretion (8). $\mathrm{D}_{2} \mathrm{O}$ dosing was either initiated the day prior to tumor cell injection or 6 days after as indicated in the figure legend. For the dose-escalation study, mice received 1-4 bolus injections within 7 days prior to tumor cell injection and were subsequently provided $8 \%, 16 \%$ and $32 \% \mathrm{D}_{2} \mathrm{O}$ drinking water to achieve targeted concentrations of $4 \%, 8 \%$ and $16 \% \mathrm{D}_{2} \mathrm{O}$, respectively in TBW based on previous publications (8). Regular drinking water served as a control $\left(0 \% \mathrm{D}_{2} \mathrm{O}\right)$.

\section{Urine/serum sample collection for HS-GC-NCI analysis}

Urine and blood sampling can be used interchangeably to quantify total body water $\mathrm{D}_{2} \mathrm{O}$ enrichment as previously shown (17). As mice recovered from anesthesia on a heating plate, $~ 50$ $\mu \mathrm{l}$ of urine was collected on a sheet of parafilm upon spontaneous passage. The urine was immediately transferred to a plastic microcentrifuge tube. When serum was used, it was collected via mandibular or retroorbital bleed and allowed to clot for $30 \mathrm{~min}$ at room temperature. The samples were spun down at 2,655 x g (5417R, Eppendorf) and the supernatant was transferred to a new microcentrifuge tube. Urine and serum samples were stored at $-20^{\circ} \mathrm{C}$ until TBW $\mathrm{D}_{2} \mathrm{O}$ enrichment analysis using headspace gas chromatography-negative chemical ionization mass spectrometry (HS-GC-NCl-MS) was performed as previously published (17).

\section{Tissue sample collection and preparation for GC-MS/MS enrichment analysis}

To determine the isotopological enrichment of deuterium in the DNA base deoxyadenosine (dA), tissue samples from HT-29 tumors or anterior thigh muscle of the contralateral hind limb were excised immediately post-mortem after imaging and stored at $-80^{\circ} \mathrm{C}$. 
Subsequently, we used a modified version of our validated GC-MS/MS method for analysis(18). Briefly, after isolating DNA from mouse tissue samples using a tissue DNA extraction kit (Maxwell ${ }^{\circledR}$ 16, Promega), the purified DNA was incubated and hydrolyzed enzymatically (EpiQuik, Epigentek Group Inc.) to its nucleoside bases (e.g. dA, dT). The method employed solid phase extraction (Waters HLB) to extract and purify dA (unlabeled and deuterium labeled) from leg muscle and tumor tissue, with automated on-line methylation (derivatization) and rapid chromatographic analysis ( 6 min) using an Agilent GC-MS/MS system (7890A GC, LTM Series II Fast GC Module, 7000C GC-MS/MS Triple Quadrupole, 7693 Autosampler and 7697A Headspace Sampler, all Agilent Technologies). The prepared samples were injected into the GC using the following conditions $\left(1 \mu \mathrm{L}\right.$ pulsed split-less injection at $235^{\circ} \mathrm{C}$; component separation using low thermal mass DB-17MS column $15 \mathrm{~m} \times 0.25 \mathrm{~mm}$ ID $\times 0.25 \mu \mathrm{m}$ film with column oven temperature program from $50-320^{\circ} \mathrm{C}$ at $120^{\circ} \mathrm{C} / \mathrm{min}$ ). The MS utilized positive chemical ionization ( $\mathrm{PCl}$ with isobutane reagent gas) and full scan mode (150 to $350 \mathrm{Da}$ ) to acquire MS data for evaluation.

As depicted in Supplementary Fig. 1B and C, MS overlays (normalized) of methylated dA and its isotopologues (e.g. $\mathrm{dA} M+1, \mathrm{dA} M+2, \mathrm{dA} \mathrm{M}+3$ etc.) depict the stable isotopes of ${ }^{13} \mathrm{C},{ }^{15} \mathrm{~N}$, ${ }^{2} \mathrm{H},{ }^{18} \mathrm{O}$ found naturally (i.e. $\sim 23 \%$ background) in methylated $\mathrm{dA}$ and its isotopologues (Supplementary Fig. 1B, contralateral leg muscle, control), as well as enrichment of $\sim 27 \%$ deuterium ( $50 \%$ minus natural isotopic background) into the DNA base $\mathrm{dA}$ of rapidly proliferating cells (Supplementary Fig. 1C, HT-29 tumor).

\section{Proton and deuterium magnetic resonance spectroscopic imaging (dMRSI)}

MRI experiments were performed on an 11.7 T (Magnex Scientific) or 9.4 T (Biospec 94/30) MRI equipped with a Bruker Avance or Avance III MRI console (Bruker-Biospin) and a custom, in-house built elliptical dual-resonance transmit/receive coil consisting of an inner elliptical solenoid deuterium coil and a saddle proton coil (Supplementary Fig. 2A). The mice were imaged with both legs perpendicular to the B0 field. The homogeneity of both coils was tested using a tight fitting 3-D printed customized oval bottle that contained two compartments with regular water and water enriched with $5 \% \mathrm{D}_{2} \mathrm{O}$ (Supplementary Fig. 2B).

Mice were anesthetized with isoflurane (4\% for induction and $1.5 \%-2.5 \%$ for maintenance in medical air, $500 \mathrm{ml} / \mathrm{min}$ ). During anesthesia, the respiratory rate was monitored with a pressure transducer (SA Instruments Inc.) and maintained at $60 \pm 10$ breaths per minute. Core body temperature was also monitored using a nonmagnetic rectal temperature probe (FISO) and maintained at $36 \pm 1{ }^{\circ} \mathrm{C}$ using a circulating water-warming pad. Immediately following anesthesia, both hind limbs were placed into the ${ }^{1} \mathrm{H} /{ }^{2} \mathrm{H}$ coil. A 3-mm diameter phantom tube $10 \%$ $\mathrm{D}_{2} \mathrm{O}$ in $\mathrm{H}_{2} \mathrm{O}(\mathrm{v} / \mathrm{v})$ was placed adjacent to the right hind limb and was included with each scan to serve as a deuterium reference signal.

For dMRS imaging, three slices of $0.5 \mathrm{~mm} \times 0.5 \mathrm{~mm} \times 3 \mathrm{~mm}$ in size were acquired by chemical shift imaging without ${ }^{1} \mathrm{H}$ decoupling using standard linear k-space encoding with a $397 \mathrm{~ms}$ repetition time, $512 \mathrm{FID}$ points, and a sweep width of $4,000 \mathrm{~Hz}$. Due to difficulties in proper phase adjustment arising from the susceptibility artifact near the $\mathrm{D}_{2} \mathrm{O}$ glass tube in the HT-29 images (Fig. 2 and 3), the spectra in each voxel were processed in magnitude mode. MiaPaCa$2 \mathrm{MRI}$ images (Fig. 4) were therefore acquired without a phantom vial attached to the leg. The images collected in a $64 \times 64$ matrix were then zero-filled to a final size of $128 \times 128 \times 3$. The total scan time was 27 minutes.

To increase the sensitivity to the weak background $\mathrm{D}_{2} \mathrm{O}$ signal, a noise reduction algorithm was employed. It takes advantage of the repeating structure of the data by decomposing the 4D image into a multilinear combination of vectors representing spectra and image columns and rows by low rank Tucker Decomposition. The algorithm uses 32 spectral vectors, 32 image vectors in 
each direction and all 3 slice vectors to reconstruct the original the $512 \times 128 \times 128 \times 3$ image (19). Using this method, $92 \pm 4 \%$ of the variance was captured in each scan, with the residual approximately corresponding to the noise level by visual analysis. Noise reduction was primarily required to detect the weaker $\mathrm{D}_{2} \mathrm{O}$ signal at $4.6 \mathrm{ppm}$ - maps of the stronger metabolite signal at $1.8 \mathrm{ppm}$ were similar in the presence and absence of noise reduction. The water peak from HDO was set to $4.6 \mathrm{ppm}$ relative to the DSS value, following a temperature correction to $37^{\circ} \mathrm{C}(20)$. No signal was detected when $\mathrm{D}_{2} \mathrm{O}$ labeling was omitted (Supplementary Fig. 2C). The anatomical imaging was performed using the following parameters: spin-echo sequence (RARE, rapid acquisition with refocused echoes), TR/TE $=500 \mathrm{~ms} / 8 \mathrm{~ms}$, with the same geometry as chemical shift imaging but with a matrix size of $128 \times 128$.

To compare metabolism between tumor and non-tumor areas, a spectrally selective image was first formed by summing the 10 points $(156 \mathrm{~Hz})$ on either side of the two major peaks in the spectra after noise reduction. A region of interest was then drawn around the right and left leg for each of the three slices in ImageJ (21). The mean greyscale value was tabulated for each region and a ratio between the signal intensity of the tumor-injected and the normal leg was calculated for both spectrally selective images.

\section{Ex vivo NMR}

Metabolites from tumor sections frozen at $-80{ }^{\circ} \mathrm{C}$ were subjected to three-phase separation to produce a polar phase, an insoluble protein interphase and a non-polar phase containing lipids using modifications to a previously published procedure for cell extracts $(22,23)$. The non-polar fraction was prepared for deuterium NMR by dissolving the lyophilized powder in $75 \%$ chloroform $/ 25 \%$ methanol, with $5 \%$ deuterated chloroform present for the frequency lock. Samples for proton NMR were prepared in deuterated $75 \%$ chloroform $/ 25 \%$ methanol. Polar samples were dissolved in $90 \% \mathrm{H}_{2} \mathrm{O} / 10 \% \mathrm{D}_{2} \mathrm{O}$. Spectra were recorded at $16.4 \mathrm{~T}$ at $20^{\circ} \mathrm{C}$ in a Bruker spectrometer equipped with a $3 \mathrm{~mm}$ triple inverse resonance cryoprobe. 512 transients were acquired for each sample. A presaturation sequence was used for the proton spectra with a relaxation delay of 6 seconds, a pulse acquire sequence was used for the deuterium spectra with a relaxation delay of 2 seconds.

\section{Statistical analysis and software}

For HS-GC-MS/MS operation, data acquisition and processing, we utilized a PC workstation with Agilent MassHunter Acquisition (B.07.06.2704), Quantitative (B.08.00) and Qualitative (B.07.00, Service Pack 1) software. Data were analyzed and visualized using GraphPad Prism 8.0. All graphs represent the mean value \pm SEM. Statistical analysis was performed as indicated in the figure legends with $p<0.05$ considered significant. 


\section{Results}

\section{$\mathrm{D}_{2} \mathrm{O}$ uptake leads to a dose-dependent increase of isotopologically labeled} deoxyadenosine in tumor cells

Water is a substrate for multiple biosynthetic pathways required for cell proliferation, including amino acid (proteins, peptides), nucleic acid (DNA, RNA), and fatty acid (lipids) synthesis (Fig. 1A). When deuterated water is administered systemically, biomolecules within rapidly proliferating cells incorporate deuterium; hence, deuterium enrichment can serve as a proxy for cell proliferation $(8,9,13,24-26)$. Using a quantitative gas chromatography tandem mass spectrometry (GC-MS/MS) method, we measured deuterium enrichment of deoxyadenosine (dA) in xenografted tumors following 7 and 14 days of in vivo tumor growth during concurrent $\mathrm{D}_{2} \mathrm{O}$ labeling $(13,17,18)$. The contralateral quadriceps muscle was excised to serve as control tissue for the GC-MS/MS analysis. In addition, we collected urine and serum samples from each study animal on the day of imaging to measure total body water (TBW) deuterium enrichment via headspace (HS)-GC-MS (17), which was confirmed to be $\sim 6-9 \%$ for all animals that underwent imaging.

The natural isotopic background in deoxyadenosine, resulting mainly from the natural abundance of ${ }^{2} \mathrm{H},{ }^{13} \mathrm{C},{ }^{15} \mathrm{~N}$ and ${ }^{17} \mathrm{O}$, ranges from $23 \%$ to $26 \%$ in both tumor without $\mathrm{D}_{2} \mathrm{O}$ labeling and muscle tissue (Fig. 1B). Deoxyadenosine extracted and purified from the tumors of mice receiving maintenance deuterated water of increasing concentrations $(0 \%, 8 \%, 16 \%$ and $32 \%)$ showed a dose-dependent linear increase in isotopologue enrichment of dA.

A

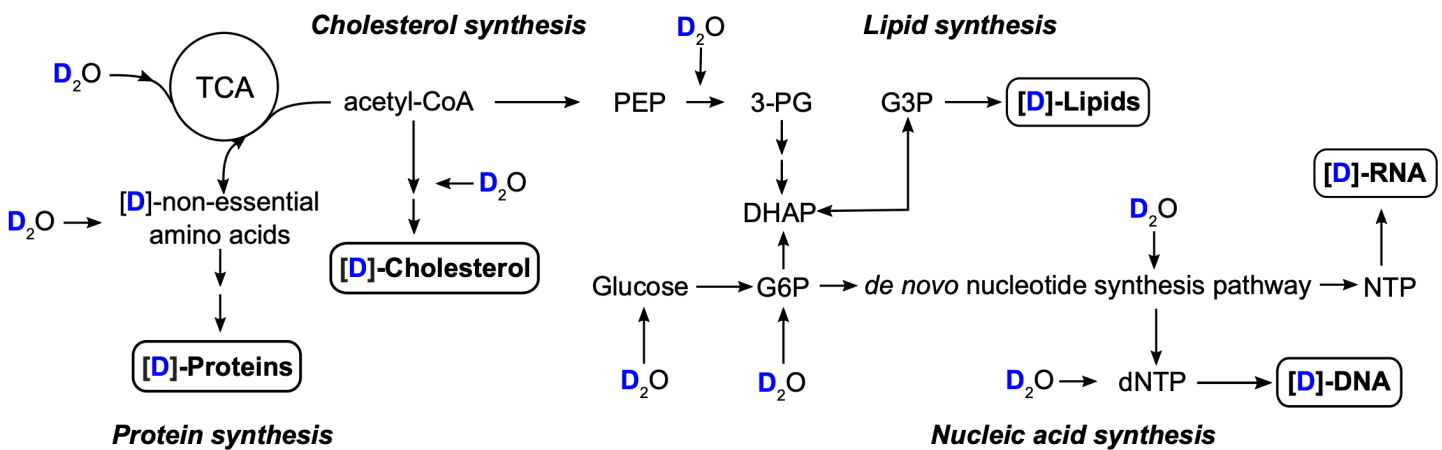

B

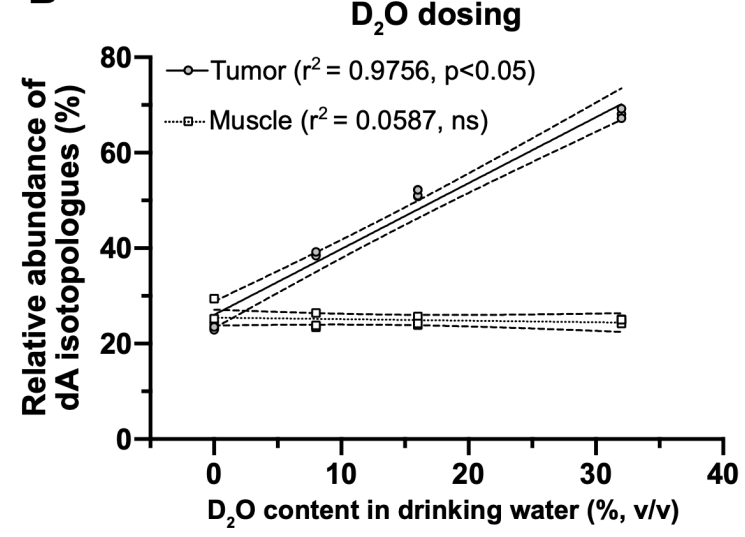

C

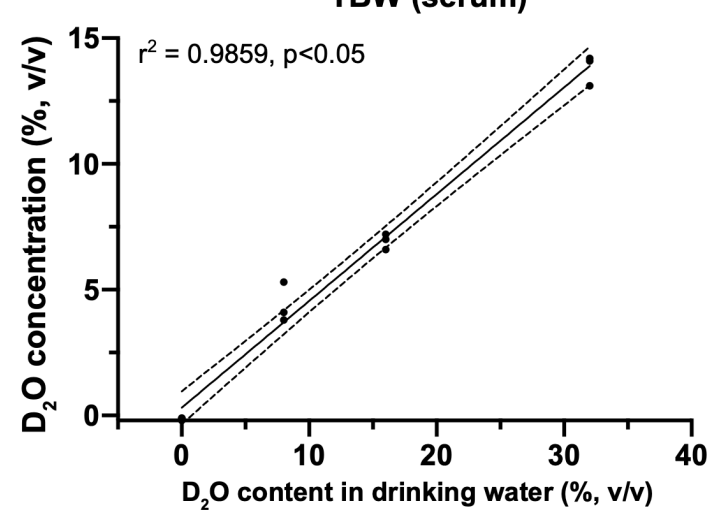

Figure 1: $\mathrm{D}_{2} \mathrm{O}$ is incorporated into biomolecules and leads to a dose-dependent increase in the isotopologue abundance of $d A$. A) Schematic illustration of biosynthetic pathways in a cell that utilize water and are therefore 
possible routes for nonexchangeable, stable deuterium incorporation into carbon-deuterium bonds. $P E P$, phosphoenolpyruvate; 3-PG, 3-phosphoglycerate; DHAP, dihydroacetone-phosphate; G6P, glucose-6-phosphate; G3P, glycerol-3-phosphate; (d)NTP, (deoxy)nucleoside triphosphate. B) Dose-dependent increase of $d A$ isotopologue abundance $(d A m+1, m+2, m+3, m+4$ and $m+5)$. Mice were injected with human HT-29 adenocarcinoma tumor cells $\left(1 \times 10^{6}\right)$ in the right hind limb and labeled with increasing concentrations of $D_{2} \mathrm{O}$ by injection of up to four i.p. boluses $\left(35 \mathrm{ml} / \mathrm{kg}, 0.9 \% \mathrm{NaCl}\right.$ in $\left.100 \% \mathrm{D}_{2} \mathrm{O}\right)$ followed by the administration of $\mathrm{D}_{2} \mathrm{O}$ in drinking water for maintenance dosing $(0-$ $32 \%, v / v)$. Two weeks after tumor cell implantation, the tumors as well as muscle tissue of the contralateral hind limb serving as a negative control were excised. The DNA was isolated and dA isotopologue abundance was quantified via GC-MS/MS. Statistical testing was performed using linear regression ( $n=3$ per group). C) The $D_{2} \mathrm{O}$ concentration in total body water was quantified using serum samples collected via mandibular or retroorbital bleed after a two-week labeling period with increasing concentrations of $D_{2} \mathrm{O}$. The quantification was carried out using a headspace GC-MS method and statistically tested using linear regression ( $n=3$ per group).

This increase in $\mathrm{dA}$ isotopologue enrichment above natural isotopic background was not detected in muscle tissue of the contralateral leg (Fig. 1B). Metabolic labeling of cellular biomass with $8 \% D_{2} \mathrm{O}$ as maintenance dose (in drinking water) resulted in $\sim 5 \% \mathrm{D}_{2} \mathrm{O}$ in TBW and a tumor deuterium enrichment of $38.7 \% \pm 0.2$ after two weeks of labeling (Fig. 1B, C). Higher maintenance doses of $\mathrm{D}_{2} \mathrm{O}$ led to an increased TBW and tumor dA enrichment, i.e. $16 \% \mathrm{D}_{2} \mathrm{O}$ resulted in $\sim 7 \%$ TBW and $51.3 \% \pm 0.4 \mathrm{dA}$ isotopologue enrichment and $32 \% \mathrm{D}_{2} \mathrm{O}$ resulted in $\sim 14 \%$ TBW and $68.2 \% \pm 0.6 \mathrm{dA}$ isotopologue enrichment, respectively (Fig. 1B, C). Meanwhile, the isotopologue enrichment of $\mathrm{dA}$ isolated from the contralateral muscle tissue (control) remained stable at around $24 \%$ for the full range of tested TBW $\mathrm{D}_{2} \mathrm{O}$ concentrations (Fig. 1B), confirming that $\mathrm{D}_{2} \mathrm{O}$ preferentially labeled tumor cells. Additionally, we found that the use of $8 \%, 16 \%$, and $32 \% \mathrm{D}_{2} \mathrm{O}$ in drinking water led to multiple deuterium atoms being incorporated into the $\mathrm{dA}$ molecule, with more than half of $d A$ molecules containing more than one deuterium atom (e.g. $d A M+2, M+3$, Supplementary Fig. 1A). Although we can reliably quantify the deuterium enrichment via mass spectrometry, the analysis is carried out ex vivo and requires a tissue sample. In a clinical setting, acquiring tissue biopsies can be difficult and there are situations where the tumor is inaccessible, or the biopsy is otherwise medically inadvisable.

\section{Deuterium incorporated into biomolecules during $\mathrm{D}_{2} \mathrm{O}$ labeling is detectable by dMRSI}

In addition to clinical contraindications for biopsy, the heterogeneity and variability in metabolic activity within a tumor may result in inconsistent deuterium quantification depending on the specific region sampled $(27,28)$. Due to these limitations, we pursued the development of an imaging modality that would circumvent the clinical risks and potential sampling error of the biopsy approach. We hypothesized that in vivo imaging of deuterium following biosynthetic labeling would allow noninvasive detection and monitoring of molecular pathways distinct from those visualized with current techniques such as FDG-PET or hyperpolarized ${ }^{13} \mathrm{C}-\mathrm{MRI}$. DNA itself is unlikely to be detected via MRI due to its short T2 and long T1 relaxation rates stemming from its size and relative stiffness. However, other metabolic intermediates enriched with deuterium may be detected, if they accumulate within the tumor in sufficient abundance $(29,30)$. We therefore set out to evaluate whether higher deuterium content within tumors compared to healthy normal tissue, as a result of increased biosynthetic rates of the former, would allow distinct visualization of tumors via dMRSI. 
A

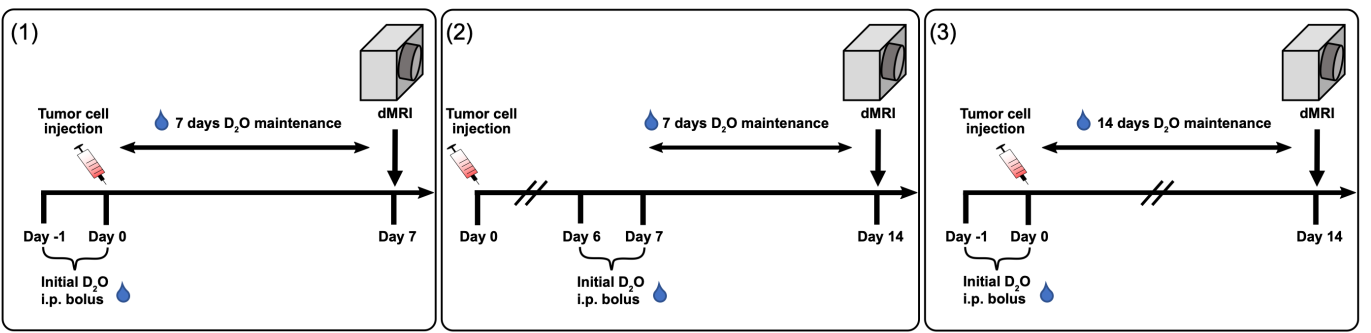

B
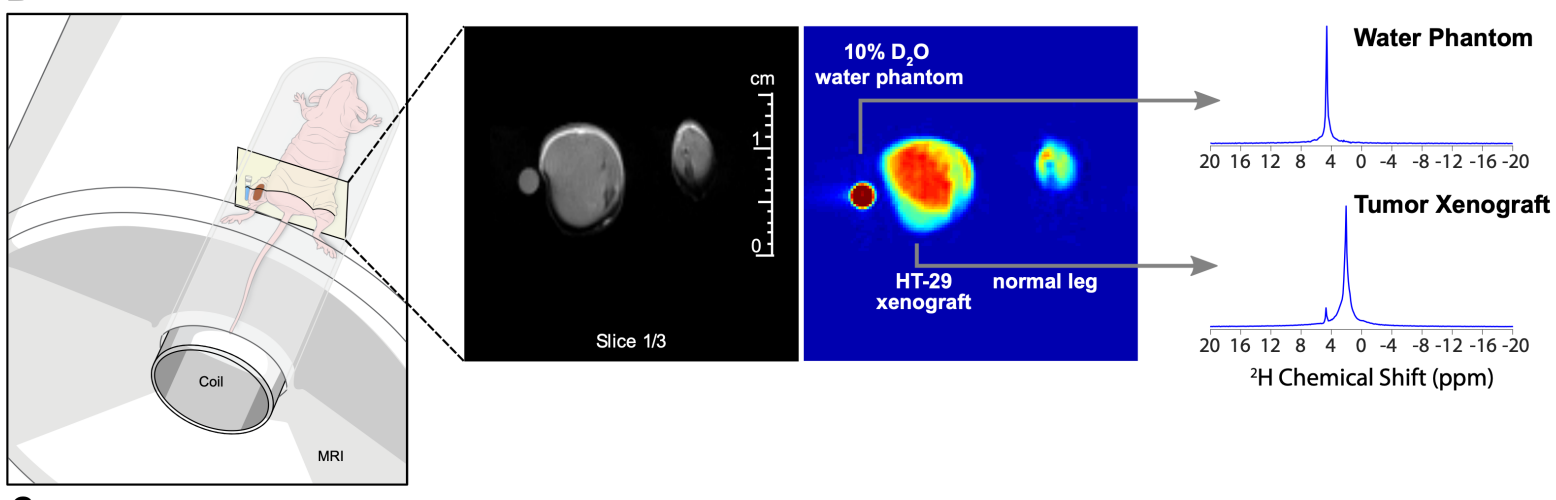

C
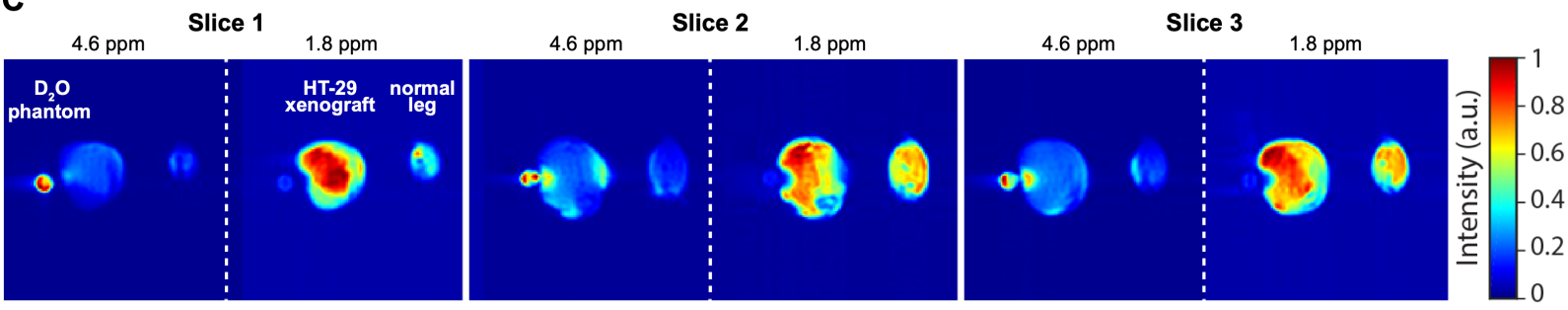

Figure 2: dMRSI chemical shift imaging of xenografted HT-29 tumors in mice at 11.7T.A) Labeling protocol for imaging experiments. Mice that underwent imaging were either labeled with two i.p. bolus injections (35 ml/kg $0.9 \%$ $\mathrm{NaCl}$ in $\left.100 \% \mathrm{D}_{2} \mathrm{O}\right) 24 \mathrm{~h}$ apart on day -1 and $0(1+3)$ or on day 6 and 7 (2) and were subsequently provided a $16 \% \mathrm{D}_{2} \mathrm{O}$ maintenance dose in drinking water for $7(1+2)$ or 14 days (3) after tumor implantation. Human HT-29 adenocarcinoma cells $\left(1 \times 10^{6}\right)$ were subcutaneously injected on day 0 into the right hind limb of athymic Foxn $1^{\text {nu }}$ mice. B) Illustration of the imaging setup (left) with a representative deuterium image (right) along with the corresponding anatomical proton MRI image (center) for labeling protocol (3). Chemical shift imaging was used to acquire a $64 \times 64$ grid of deuterium spectra with each spectrum corresponding to a voxel $0.5 \mathrm{~mm} \times 0.5 \mathrm{~mm} \times 3 \mathrm{~mm}$ in size. The deuterium image was formed by summing across the entire spectra while the spectra corresponding to the individual voxels indicated are shown on the right (top, $\mathrm{D}_{2} \mathrm{O}$ phantom; bottom, tumor xenograft). The anatomical imaging was acquired using a spinecho sequence with TR/TE $=500 \mathrm{~ms} / 8 \mathrm{~ms}$ and the same geometry as chemical shift imaging but with a matrix size of 128 x 128. C) Spectrally selective images for the mouse from (b) corresponding to the two major peaks at 4.6 ppm $\left(D_{2} \mathrm{O}\right.$ chemical shift) and $1.8 \mathrm{ppm}$.

We performed in vivo labeling on mice injected with HT-29 tumors followed by dMRSI detection (Fig. 2A). Figure 2B shows a representative slice from the image of both hind limbs of a female athymic mouse with the left leg bearing a relatively small $(<1 \mathrm{~cm}) \mathrm{HT}-29$ tumor xenograft taken 14 days after tumor cell injection with concurrent deuterated water labeling to $8 \%$ TBW. A 3-mm NRM capillary tube containing $10 \% \mathrm{D}_{2} \mathrm{O}$ near the left leg served as a reference for the frequency of the water signal at $\sim 4.6 \mathrm{ppm}$. Two major peaks can be detected in the deuterium spectra. The first is centered at $4.6 \mathrm{ppm}$ near the expected frequency of the $\mathrm{HDO} / \mathrm{D}_{2} \mathrm{O}$ water peak (top). There is a close correspondence between the anatomical MRI and the deuterium image at the water frequency, indicating background TBW deuterium enrichment is similar between the tumor-bearing limb and the unmanipulated limb (Fig. 2C). The remaining, non-water derived signal is characterized by an intense peak (mean SNR 150) with a chemical shift of $\sim 1.8 \mathrm{ppm}$ 
(Fig. 2B, bottom spectrum) that is primarily, but not exclusively, observed in the tumor region. Figure $2 \mathrm{C}$ shows an example of all three slices acquired and separated into the two distinct frequencies, demonstrating that the tumor deuterium signal is not attributable to free $\mathrm{D}_{2} \mathrm{O}$. In all three slices, the deuterium signal intensity at $1.8 \mathrm{ppm}$ is highest in the tumor bearing limb. The exact identity of the peak cannot be directly inferred from MRI, but the shift indicates that the peak likely originates from the resonance of alkyl groups, taking into account the slight chemical shift offset from $\mathrm{B}_{0}$ distortion caused by proximity to the partially filled $\mathrm{D}_{2} \mathrm{O}$ phantom vial (31).

\section{dMRSI distinguishes tumors from normal tissue}

To detect deuterium-labeled metabolites in vivo, we tested several labeling-imaging protocols. Throughout the tested experimental schemas, we consistently observed a stronger deuterium signal at $\sim 1.8 \mathrm{ppm}$ in the tumor region compared to the contralateral limb (Fig. 3A). The degree of contrast, however, was dependent on both the length and timing of the labeling period (Fig. 3B). The strongest contrast (median=1.40, $p=0.02$ on a per mouse basis, Wilcox's signed rank test), quantified as a ratio of the mean grey value between the HT-29-injected and normal leg, was observed after 14 days of tumor growth with labeling starting on the $6^{\text {th }}$ day (labeling schema (2) in Fig. 2A, cyan squares in Figure 3B). Limiting both growth and labeling to the first 7 days (labeling schema (1) in Fig. 2A) led to negligible contrast (median=0.96, $p=0.81$ ). A similar trend was observed in an independent experiment performed on a $9.4 \mathrm{~T} \mathrm{MRI}$ (Supplementary Fig. 3). Labeling for the full 14-day tumor growth period (labeling schema (3) in Fig. 2A) decreased contrast relative to starting at the 6 -day midpoint (median=1.20, $p=0.11$ ). No significant difference in contrast was observed comparing the signal intensity at $4.6 \mathrm{ppm}$ for any labeling protocol. Interestingly, while the MRI contrast was strongly dependent on the labeling period, the degree of deuterium labeling in both $\mathrm{dA}$ and in TBW was nearly independent of the labeling period (Fig. 3C, D). 


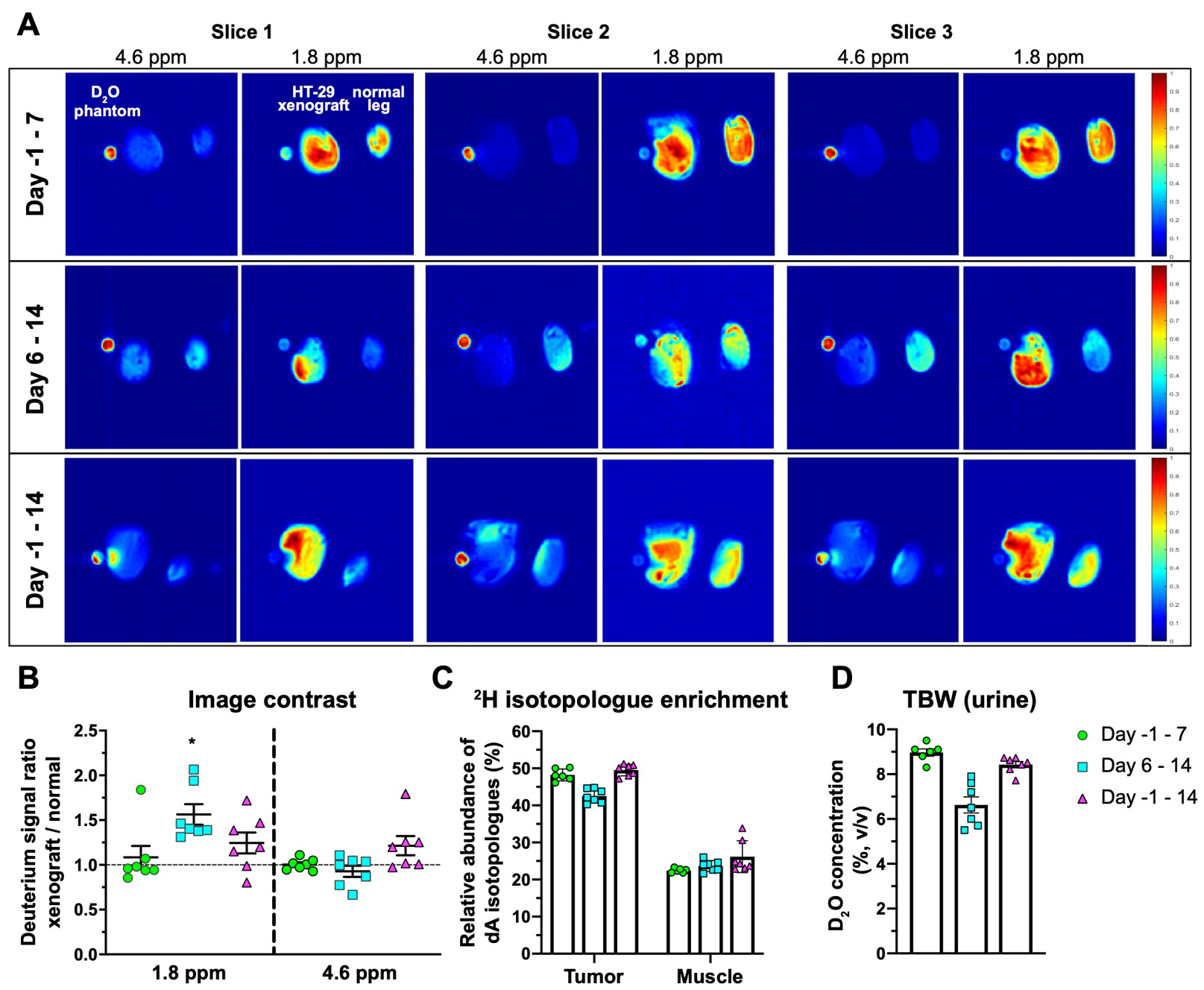

Figure 3: Comparison of different labeling strategies for dMRSI detection of HT-29 tumors. A) Representative images of the three labeling protocols shown as spectrally separated images for the $1.8 \mathrm{ppm}$ and $4.8 \mathrm{ppm}$ (water) peaks across three slices of HT-29 tumors acquired on a 11.7T scanner. B) Quantification of the contrast between tumor and control hind legs for the labeling schemas defined in Fig. 2a summed across the leg volume for the aliphatic $(1.8 \mathrm{ppm})$ and water (4.6 ppm) signal regions. The leg area was defined as an $\mathrm{ROI}$, the mean grey value was measured within and expressed as a ratio between the HT-29-injected and normal leg. Statistical analysis was performed using a Wilcoxon signed rank test against a hypothetical median of one, ${ }^{*}=p<0.05, n=7$ per group. C) Relative abundance of $d A$ isotopologues after a 7-day or 14-day labeling period in tumor and muscle tissue ( $n=6-7$ per group) analyzed via GC-MS. D) The $D_{2} \mathrm{O}$ concentration in total body water was quantified using urine samples collected after 7 and 14 days of labeling via HS-GC-MS, $n=6-7$ per group.

To validate our findings, we tested the most promising labeling strategy (d $6-14)$ in a second xenograft model using the pancreatic cancer cell line MiaPaCA-2 (Fig. 4). Tumor cells were again subcutaneously injected into the right hind leg and imaged after 14 days. As previously demonstrated with the HT-29 cell line, deuterium labeling from day 6 to 14 provided a significant contrast, enabling a clear distinction between the tumor-injected leg and the contralateral limb (Fig. 4A, B). In contrast to HT-29 tumors, MiaPaCa-2 tumors are easily identifiable on the anatomical MRI and the comparison of the deuterium signal with the anatomical image confirmed that the highest deuterium signal originates in the tumor tissue. Of note, other hyperintense anatomical structures such as tendons or the subcutaneous fat were not detectable in the deuterium image (Fig 4A, white arrows). 
A
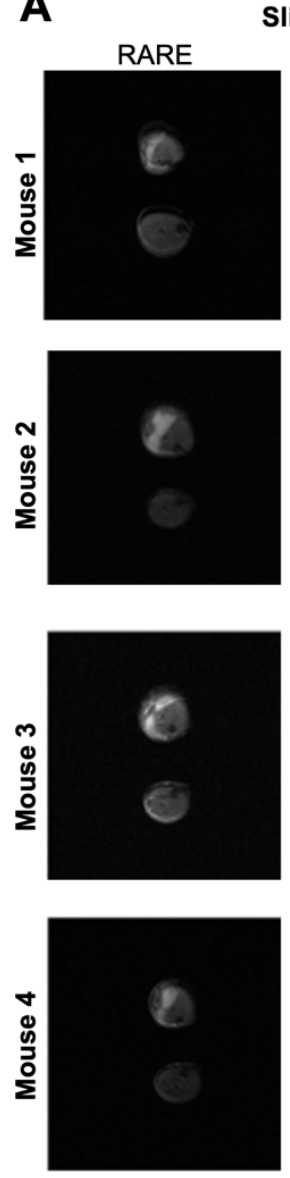

Slice 1
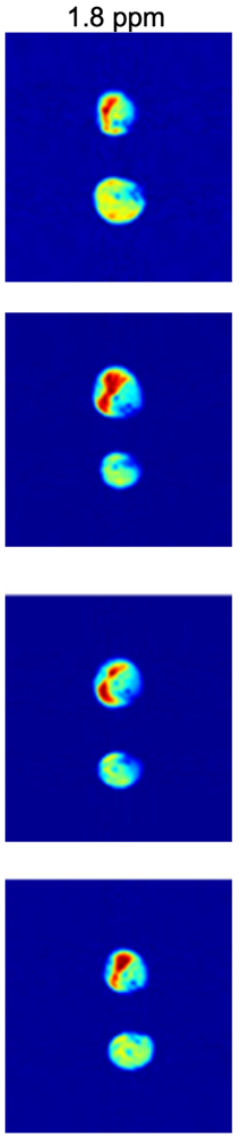

Slice 2
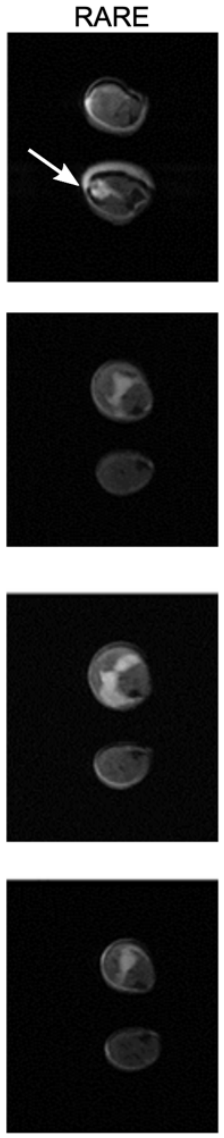

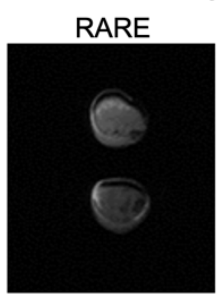

Slice 3
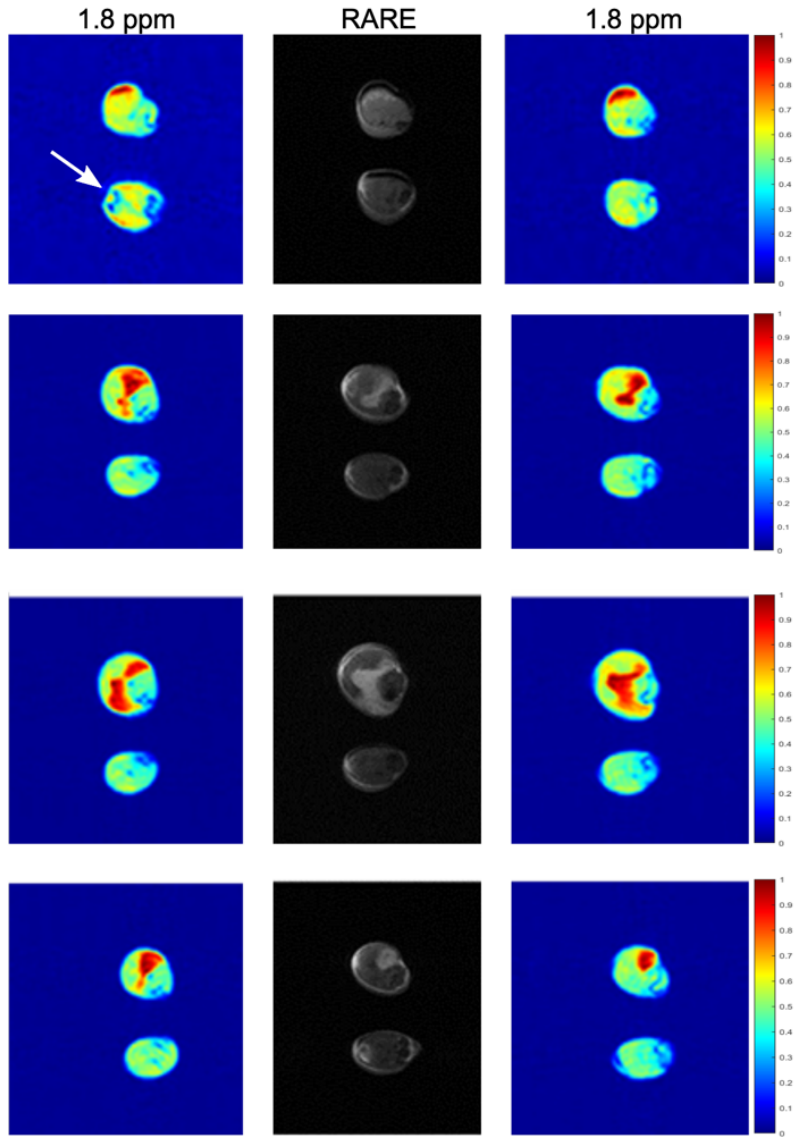

B

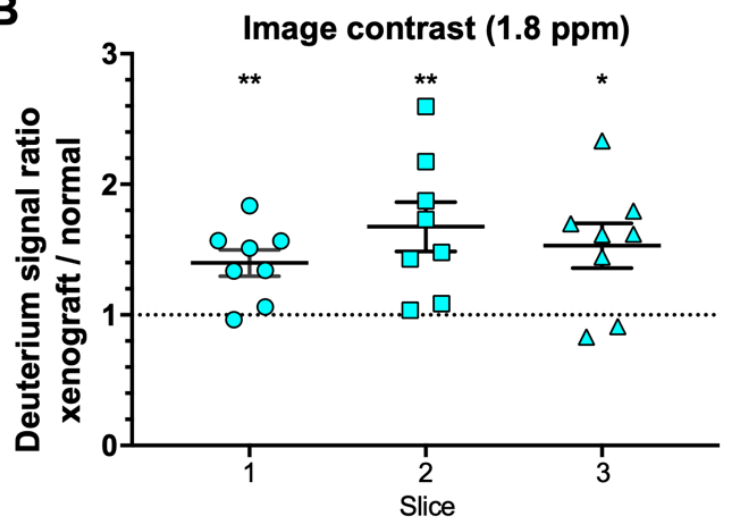

Figure 4: Detection of MiaPaCa-2 tumors via dMRSI. A) Paired RARE anatomical and deuterium images of 4 representative mice at $1.8 \mathrm{ppm}$ of the MiaPaCa-2 xenograft-injected leg (top) and the contralateral side (bottom) after two weeks of tumor growth and $\mathrm{D}_{2} \mathrm{O}$ labeling during the second week. The white arrows indicate a hyperintense tendon present on the RARE MR image that is not detectable in the corresponding deuterium image. Images were acquired using a 9.4T scanner. B) Quantification of the contrast between tumor-bearing and control hind legs for the labeling schemas 2 as defined in Fig. $2 A$ summed across the leg volume for the aliphatic (1.8 ppm) signal region for each of the three acquired images per mouse. Statistical analysis was performed using a one sample test against a hypothetical median of one, $n=8,{ }^{*}=p<0.05,{ }^{* *}=p<.0 .01$. Error bars indicate the SEM. 


\section{dMRSI signal from $\mathrm{D}_{2} \mathrm{O}$ labeling originates from cholesterol}

The deuterium signal at $\sim 1.8 \mathrm{ppm}$ likely arises from alkyl groups, but due to the spectral overlap in this region and the limited in vivo resolution the peak cannot be assigned to a specific metabolite. To more definitively assign the peak, tumors were excised, and flash frozen at the end of the labeling period immediately following imaging. The polar and non-polar fractions were separated and analyzed by deuterium NMR (Fig. 5). No significant peaks were detected in the deuterium spectrum of the polar fraction beyond the HDO solvent signal (data not shown), suggesting TCA cycle intermediates and amino acids are rapidly cycled and do not accumulate to a substantial degree within the experimental timeframe. Within the non-polar fraction, no signal outside of those of the solvent could be detected in an unlabeled tumor or for the day -1-7 labeling period (Fig. 5B-D), in concordance with the weak signal observed by in vivo dMRSI. When labeling occurs during the period of rapid tumor growth, two peaks at $0.7 \mathrm{ppm}$ and $1.1 \mathrm{ppm}$ could be detected with $\mathrm{D}_{2} \mathrm{O}$ labeling for both HT-29 (Fig. 5F, H) and MiaPaCa-2 xenografts (Fig. 5E, G). The peak at $0.7 \mathrm{ppm}$ occurs in an empty region of the corresponding proton spectra and as such can be immediately identified as the distinctive high intensity singlet peak of the methyl group of carbon 18 of cholesterol and cholesterol esters based on previously assigned spectra $(32,33)$. The peak at $1.1 \mathrm{ppm}$ occurs in a somewhat more crowded region and is less distinctive but is consistent with the corresponding C19 methyl group. Only a minor peak for the cholesterol ester was detected in a muscle sample from the contralateral limb (Fig. 5I). No peaks for lipids or other non-polar molecules in either the xenograft or muscle samples were detected in the deuterium NMR, despite their presence in the proton spectra (Fig. 5A).

\section{A HT-29 Xenograft}

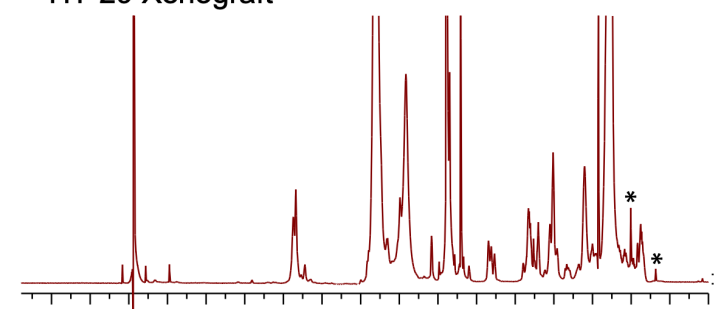

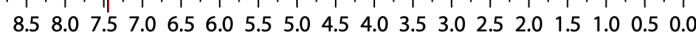
${ }^{1} \mathrm{H}$ Chemical Shift $(\mathrm{ppm})$

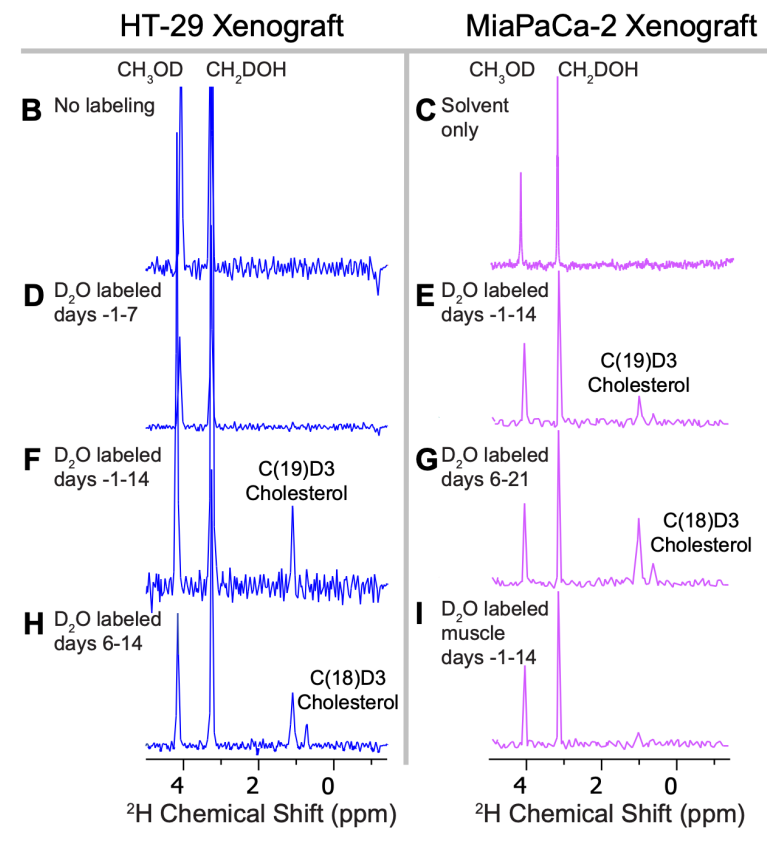

Figure 5: NMR spectra of the non-polar fraction of extracted xenografts. A) Proton NMR spectrum of the non-polar fraction from a HT-29 xenograft. Numerous peaks corresponding to lipids are visible as well as two peaks corresponding to the strong singlet signal of C(18)D3 and C(19)D3 of cholesterol and cholesterol esters (marked with *) at $0.7 \mathrm{ppm}$ and 1.1 ppm. B and C) Deuterium NMR spectrum of the nonpolar fraction from a HT-29 xenograft without $D_{2} \mathrm{O}$ labeling. No peaks are present beyond those of the solvent. $\boldsymbol{D}$ to $\boldsymbol{H})$ Non-polar fractions in the presence of $\mathrm{D}_{2} \mathrm{O}$ labeling. Peaks at the expected position for $C(18) D 3$ and C(19)D3 of cholesterol and cholesterol esters are evident in both xenografts when $\mathrm{D}_{2} \mathrm{O}$ is administered during the tumor growth period (E-H). I) Deuterium NMR spectrum of the non-polar fraction from muscle tissue from the contralateral limb. Only a weak signal from labeled cholesterol esters is evident. Spectra are referenced to the $\mathrm{CDCl}_{3}$ peak at $7.23 \mathrm{ppm}$. Intensities are normalized to the dry protein weight of the sample. No peaks of any type were found in the corresponding polar fractions. 


\section{Discussion}

The first published use of deuterium in MRI was described in 1986 (34). Initial studies on dMRS showed that although deuterium has a natural abundance of only $0.015 \%$ and a gyromagnetic ratio that is $1 / 6^{\text {th }}$ of a proton, other properties, such as its short T1 relaxation time that allows for quicker signal averaging, can compensate for the less favorable MRI-relevant factors (34). Deuterium MRI has since been used to visualize blood flow within a variety of tissues in animal models, including tumors (35-38). In contrast to our approach, most studies of this type used a single bolus injection of deuterated water to trace the deuterium signal in the organ of interest over a short time frame of minutes to hours. This enabled the visualization of blood flow and vasculature allowing the evaluation of tumor perfusion, but perfusion alone does not discriminate between healthy tissue and tumor. Continuous labeling with deuterium rather than administering a bolus of deuterium-labeled metabolite enabled us to enrich the tumor tissue with deuterium through biosynthesis of molecules incorporating deuterium. Unlike deuterium imaging following a single bolus injection before image acquisition, the $\mathrm{D}_{2} \mathrm{O}$ in our protocol had equilibrated with the TBW; i.e. we were not evaluating a perfusion difference but rather the accumulation of recently synthesized biomolecules within the tumor. We have used dA deuterium enrichment to demonstrate and quantify the degree of nucleotide labeling, which provides an estimate of the total degree of biosynthetic labeling with deuterium $(17,18)$ as DNA is rarely catabolized once synthesized (39). Deuterium has also been shown to be incorporated into other major classes of biomolecules, such as amino acids/proteins (9,24), triglycerides/lipids (40-42), glycolysis (43) and TCA cycle intermediates (44). Therefore, we inferred that many biomolecules are labeled with deuterium during the experiment, and likely at multiple sites (see Supplementary Fig. 1B). However, the labeled molecules are also subject to excretion and conversion into other metabolites as time progresses. Furthermore, the metabolism of tumors is not closed but contains substantial contributions from circulating molecules synthesized elsewhere. The localized deuterium signal of a particular metabolite is therefore a measure of the net accumulation at the site from all internal and external sources from molecules synthesized within the specified timeframe.

By testing different labeling schemas, we found that labeling from day $6-14$ provided the highest contrast between the tumor-injected leg and the contralateral control. During this time period, the tumor doubles in size resulting in high deuterium enrichment and thus a readily detectable tumor (16). More prolonged labeling with $\mathrm{D}_{2} \mathrm{O}$ reduced the contrast between the proliferating tumor and muscle in the contralateral limb. Although the muscle tissue showed no significant increase in isotopologue enrichment of $\mathrm{dA}$ after two weeks of labeling, other biomolecules that contribute to the imaging but are not readily turned over, i.e. lipids and sterols, may enrich with deuterium over time. This was previously observed with long term $\mathrm{D}_{2} \mathrm{O}$ labeling of healthy tissues $(45,46)$. The labeled metabolite generated will depend on the specifics of the metabolism of the system $(42,47)$.

Within the selected labeling window, we observed accumulation of cholesterol and cholesterol esters in HT-29 (colon adenocarcinoma) and MiaPaCa-2 (pancreatic ductal adenocarcinoma) xenografts (Figs. 4 and 5). Cellular cholesterol is obtained either from circulating LDL-cholesterol in plasma by receptor-mediated uptake or by de novo synthesis within the tumor via the mevalonate pathway with acyl-CoA as the carbon source. The degree of labeling is dependent on the source. Cholesterol obtained directly from dietary sources is exogenous to the body, not subject to $\mathrm{D}_{2} \mathrm{O}$ labeling and, therefore, invisible to dMRSI. Cholesterol formed from other precursors, whether obtained by receptor mediated endocytosis of circulating cholesterol or by on-site synthesis, is likely to be heavily labeled by $\mathrm{D}_{2} \mathrm{O}(48)$. While circulating cholesterol from 
bioRxiv preprint doi: https://doi.org/10.1101/809327; this version posted May 28, 2020. The copyright holder for this preprint (which was not certified by peer review) is the author/funder. All rights reserved. No reuse allowed without permission.

dietary sources forms a large fraction of total cholesterol in most normal tissues, de novo synthesis of cholesterol is strongly upregulated in many tumors (49) from proteolytic cleavage of sterol regulatory element binding proteins (SREBPs) in response to p53, RAS, or mTOR activation (50) originating from oncogenic mutations or hypoxic conditions and other environmental stressors. Concurrently, cholesterol efflux is often reduced via downregulation of the ATP-binding cassette transporter A1 (ABCA1) through the effects p53 and RAS on DNA hypermethylation (51). The result is a net accumulation of cholesterol in the membranes and cholesterol esters in lipid droplets. Membrane cholesterol is likely not detectable in MRI due to excessive signal broadening from restricted motional averaging within the bilayer. Cholesterol esters in lipid droplets, by contrast, are relatively mobile and are expected to give sharp MRI signals (31). Surprisingly, we saw little evidence of labeled lipids (Fig. 5), another major potential synthetic route for long term storage.

Cholesterol accumulation within the tumor has many consequences (50). High levels of cholesterol in the mitochondrial membrane alter its physical properties, inhibiting the mitochondrial permeability transition as well as the activation of apoptosis by limiting the release of cytochrome C (52). Cholesterol binding directly activates mTORC1 (53), the Smoothened receptor (54), and multiple signaling proteins containing PDZ domains with the CRAC motif (55) resulting in the activation of several major pathways associated with cell division, differentiation, invasion, and metastasis including the MAPK/ERK, Hedgehog, PI3K/Akt, and Wnt/ß-catenin pathways (50). Indirectly, high levels of membrane cholesterol can facilitate the association of aberrant signaling complexes through the excessive formation of lipid rafts (56). Given the multiple oncogenic pathways cholesterol affects, it is not surprising that cholesterol levels are often strong predictors of cancer progression (57) and that modulating cholesterol metabolism is an active target for drug development.

Since cholesterol can be derived from many sources, drug development targeting cholesterol metabolism is contingent on reliable methods for the measurement of cholesterol uptake, synthesis, and accumulation. The primary method for cholesterol imaging is currently the SPECT tracer NP-59, an ${ }^{131}$ I cholesterol analogue (58). As a SPECT tracer, NP-59 measures levels of cholesterol uptake, but not de novo synthesis, which is an important part of cholesterol metabolism in many tumors (49). By imaging accumulation of synthesized cholesterol, deuterium imaging offers a window into an important aspect of tumor metabolism that has been difficult to access by imaging techniques to date.

From a clinical translation standpoint, deuterium MRI is inexpensive with regard to label and system set-up, technically straightforward regarding the design of RF coils for lower frequencies, and it can be used to evaluate multiple anatomical regions. Short-term intake of low-to-moderate concentrations of deuterium is generally considered safe for humans and longterm toxicity studies in animals have not shown any detrimental effects below $20 \%$ TBW enrichment (11). Nonetheless, some logistical considerations must be overcome for clinical implementation of this imaging approach. Clinical studies involving deuterated water administration have so far been performed at $1-2 \%$ TBW enrichment $(59,60)$. Future pre-clinical studies will test lower TBW doses of $\mathrm{D}_{2} \mathrm{O}$ labeling for this imaging approach. Given the abundance of signal observed at the current TBW labeling it is likely that the lower doses will allow imaging resolution between tumor and healthy tissue. Once the lowest systemic preclinical labeling dose is determined, pilot clinical studies will be performed to determine safety. In addition, current experiments were conducted at a high field (9.4 and 11.7 T). Given the strength of the observed dMRS signal in our preclinical study (overall mean SNR 150) and the signal gain achieved by post-acquisition processing ( 24 fold), testing our labeling/imaging protocol at lower TBW enrichments and lower magnet field strengths that are widely available 
for clinical imaging (i.e. 3 T) should be feasible. Furthermore, limb tumor xenografts were used to demonstrate the potential of the method, while future studies of dMRS imaging in orthotopic tumor models will be carried out to assess image contrast in a physiological context of complex anatomy.

In summary, we have demonstrated that $\mathrm{D}_{2} \mathrm{O}$ labeling leads to differential incorporation of deuterium into cholesterol in two distinct xenograft models that can be visualized by dMRSI in vivo. We believe that this novel imaging technique could provide an excellent addition to existing cancer imaging approaches and facilitate the analysis of tumor cell cholesterol metabolism in vivo.

\section{Acknowledgements}

We thank Dr. Nobu Oshima for technical assistance with in vivo injection of HT-29 cells and Dr. Ehydel Castro for performing phlebotomy on a subset of study animals. We acknowledge Drs. Steve J. Dodd, Martin J. Lizak, Kazutoshi Yamamoto and Danielle Donahue for assisting with MRI scan acquisition. We thank Christopher Johns for assistance with tissue processing and editing of the manuscript. We acknowledge Dr. Charles Zhu for assistance with 3D MRI coil design. We thank Ethan Tyler and Erena He, medical illustrators with NIH Medical Arts, for generating the drawing used in Figure 2. This was work was supported by $\mathrm{NCI}, \mathrm{NIH}$ intramural funding including a supplement from the $\mathrm{NCl}$ Center for Cancer Research Major Opportunity: The Metabolic Basis of Cancer.

\section{Competing interests}

NPB, DEF, NM, HM, MCK, and REG are inventors on a patent application related to this work, PCT/US2017/058886. Additionally, JRB, SK, HM, MCK are inventors on patent application pertaining to the signal-to-noise reduction algorithm, PCT/US2018/018217.

\section{$\underline{\text { References }}$}

1. Mason BR, Eastham JA, Davis BJ, Mynderse LA, Pugh TJ, Lee RJ, et al. Current Status of MRI and PET in the NCCN Guidelines for Prostate Cancer. J Natl Compr Canc Netw 2019;17:506-13

2. Hagaman MG. NCCN Imaging Appropriate Use Criteria Compendium: An Overview. J Adv Pract Oncol 2017;8:203-4

3. Lim JS, Yun MJ, Kim MJ, Hyung WJ, Park MS, Choi JY, et al. CT and PET in stomach cancer: preoperative staging and monitoring of response to therapy. Radiographics 2006;26:143-56

4. Tee SS, Keshari KR. Novel Approaches to Imaging Tumor Metabolism. Cancer J 2015;21:165-73

5. Ardenkjaer-Larsen JH. On the present and future of dissolution-DNP. J Magn Reson 2016;264:3-12

6. Jain M, Nilsson R, Sharma S, Madhusudhan N, Kitami T, Souza AL, et al. Metabolite profiling identifies a key role for glycine in rapid cancer cell proliferation. Science 2012;336:1040-4 
7. Lunt SY, Vander Heiden MG. Aerobic glycolysis: meeting the metabolic requirements of cell proliferation. Annu Rev Cell Dev Biol 2011;27:441-64

8. Busch R, Neese RA, Awada M, Hayes GM, Hellerstein MK. Measurement of cell proliferation by heavy water labeling. Nat Protoc 2007;2:3045-57

9. De Riva A, Deery MJ, McDonald S, Lund T, Busch R. Measurement of protein synthesis using heavy water labeling and peptide mass spectrometry: Discrimination between major histocompatibility complex allotypes. Anal Biochem 2010;403:1-12

10. Strawford A, Antelo F, Christiansen M, Hellerstein MK. Adipose tissue triglyceride turnover, de novo lipogenesis, and cell proliferation in humans measured with $2 \mathrm{H} 2 \mathrm{O}$. Am J Physiol Endocrinol Metab 2004;286:E577-88

11. Jones PJ, Leatherdale ST. Stable isotopes in clinical research: safety reaffirmed. Clin Sci (Lond) 1991;80:277-80

12. Klein PD, Klein ER. Stable isotopes: origins and safety. J Clin Pharmacol 1986;26:37882

13. Buxbaum NP, Farthing DE, Maglakelidze N, Lizak M, Merkle H, Carpenter AC, et al. In vivo kinetics and nonradioactive imaging of rapidly proliferating cells in graft-versus-host disease. JCI Insight 2017;2

14. De Feyter HM, Behar KL, Corbin ZA, Fulbright RK, Brown PB, Mclntyre S, et al. Deuterium metabolic imaging (DMI) for MRI-based 3D mapping of metabolism in vivo. Sci Adv 2018;4:eaat7314

15. Lu M, Zhu XH, Zhang Y, Mateescu G, Chen W. Quantitative assessment of brain glucose metabolic rates using in vivo deuterium magnetic resonance spectroscopy. $J$ Cereb Blood Flow Metab 2017;37:3518-30

16. Saito K, Matsumoto S, Takakusagi Y, Matsuo M, Morris HD, Lizak MJ, et al. 13C-MR Spectroscopic Imaging with Hyperpolarized [1-13C]pyruvate Detects Early Response to Radiotherapy in SCC Tumors and HT-29 Tumors. Clin Cancer Res 2015;21:5073-81

17. Farthing DE, Buxbaum NP, Lucas PJ, Maglakelidze N, Oliver B, Wang J, et al. Comparing DNA enrichment of proliferating cells following administration of different stable isotopes of heavy water. Sci Rep 2017;7:4043

18. Farthing DE, Buxbaum NP, Bare CV, Treadwell SM, Kapoor V, Williams KM, et al. Sensitive GC-MS/MS method to measure deuterium labeled deoxyadenosine in DNA from limited mouse cell populations. Anal Chem 2013;85:4613-20

19. Brender JR, Kishimoto S, Merkle H, Reed G, Hurd RE, Chen AP, et al. Dynamic Imaging of Glucose and Lactate Metabolism by (13)C-MRS without Hyperpolarization. Sci Rep 2019;9:3410

20. Hoffman RE. Standardization of chemical shifts of TMS and solvent signals in NMR solvents. Magn Reson Chem 2006;44:606-16 
21. Schneider CA, Rasband WS, Eliceiri KW. NIH Image to ImageJ: 25 years of image analysis. Nat Methods 2012;9:671-5

22. Kishimoto S, Brender JR, Crooks DR, Matsumoto S, Seki T, Oshima N, et al. Imaging of glucose metabolism by $13 \mathrm{C}-\mathrm{MRI}$ distinguishes pancreatic cancer subtypes in mice. Elife 2019;8

23. Crooks DR, Fan TW, Linehan WM. Metabolic Labeling of Cultured Mammalian Cells for Stable Isotope-Resolved Metabolomics: Practical Aspects of Tissue Culture and Sample Extraction. Methods Mol Biol 2019;1928:1-27

24. Busch R, Kim YK, Neese RA, Schade-Serin V, Collins M, Awada M, et al. Measurement of protein turnover rates by heavy water labeling of nonessential amino acids. Biochim Biophys Acta 2006;1760:730-44

25. Voogt JN, Awada M, Murphy EJ, Hayes GM, Busch R, Hellerstein MK. Measurement of very low rates of cell proliferation by heavy water labeling of DNA and gas chromatography/pyrolysis/isotope ratio-mass spectrometric analysis. Nat Protoc 2007;2:3058-62

26. Previs SF, McLaren DG, Wang SP, Stout SJ, Zhou H, Herath K, et al. New methodologies for studying lipid synthesis and turnover: looking backwards to enable moving forwards. Biochim Biophys Acta 2014;1842:402-13

27. Gerlinger M, Rowan AJ, Horswell S, Math M, Larkin J, Endesfelder D, et al. Intratumor heterogeneity and branched evolution revealed by multiregion sequencing. $\mathrm{N}$ Engl $\mathrm{J}$ Med 2012;366:883-92

28. Cantor JR, Sabatini DM. Cancer cell metabolism: one hallmark, many faces. Cancer Discov 2012;2:881-98

29. Griffin JL, Shockcor JP. Metabolic profiles of cancer cells. Nat Rev Cancer 2004;4:55161

30. Howe FA, Barton SJ, Cudlip SA, Stubbs M, Saunders DE, Murphy M, et al. Metabolic profiles of human brain tumors using quantitative in vivo $1 \mathrm{H}$ magnetic resonance spectroscopy. Magn Reson Med 2003;49:223-32

31. Delikatny EJ, Chawla S, Leung DJ, Poptani H. MR-visible lipids and the tumor microenvironment. NMR Biomed 2011;24:592-611

32. Oostendorp M, Engelke UF, Willemsen MA, Wevers RA. Diagnosing inborn errors of lipid metabolism with proton nuclear magnetic resonance spectroscopy. Clin Chem 2006;52:1395-405

33. Subramanian A, Shankar Joshi B, Roy AD, Roy R, Gupta V, Dang RS. NMR spectroscopic identification of cholesterol esters, plasmalogen and phenolic glycolipids as fingerprint markers of human intracranial tuberculomas. Nmr Biomed 2008;21:272-88 
34. Ewy CS, Babcock EE, Ackerman JJH. Deuterium nuclear magnetic resonance spinimaging of D2O: A potential exogenous MRI label. Magnetic Resonance Imaging 1986;4:407-11

35. Ackerman JJ, Ewy CS, Kim SG, Shalwitz RA. Deuterium magnetic resonance in vivo: the measurement of blood flow and tissue perfusion. Ann N Y Acad Sci 1987;508:89-98

36. Mattiello J, Evelhoch JL. Relative volume-average murine tumor blood flow measurement via deuterium nuclear magnetic resonance spectroscopy. Magn Reson Med 1991;18:320-34

37. Kovar DA, Lewis MZ, River JN, Lipton MJ, Karczmar GS. In vivo imaging of extraction fraction of low molecular weight MR contrast agents and perfusion rate in rodent tumors. Magn Reson Med 1997;38:259-68

38. Bogin L, Margalit R, Ristau H, Mispelter J, Degani H. Parametric imaging of tumor perfusion with deuterium magnetic resonance imaging. Microvasc Res 2002;64:104-15

39. Gerber G, Berger G, Altman KI. The catabolism of tissue nucleic acid in the rat. I. The replacement time of deoxribonucleic acid. J Biol Chem 1960;235:1433-6

40. Turner SM, Murphy EJ, Neese RA, Antelo F, Thomas T, Agarwal A, et al. Measurement of TG synthesis and turnover in vivo by $2 \mathrm{H} 2 \mathrm{O}$ incorporation into the glycerol moiety and application of MIDA. Am J Physiol Endocrinol Metab 2003;285:E790-803

41. Lee WN, Bassilian S, Guo Z, Schoeller D, Edmond J, Bergner EA, et al. Measurement of fractional lipid synthesis using deuterated water $(2 \mathrm{H} 2 \mathrm{O})$ and mass isotopomer analysis. Am J Physiol 1994;266:E372-83

42. Diraison F, Pachiaudi C, Beylot M. In vivo measurement of plasma cholesterol and fatty acid synthesis with deuterated water: determination of the average number of deuterium atoms incorporated. Metabolism 1996;45:817-21

43. Landau BR, Wahren J, Chandramouli V, Schumann WC, Ekberg K, Kalhan SC. Use of $2 \mathrm{H} 2 \mathrm{O}$ for estimating rates of gluconeogenesis. Application to the fasted state. J Clin Invest 1995;95:172-8

44. Silva AM, Martins F, Jones JG, Carvalho R. 2H2O incorporation into hepatic acetyl-CoA and de novo lipogenesis as measured by Krebs cycle-mediated $2 \mathrm{H}$-enrichment of glutamate and glutamine. Magn Reson Med 2011;66:1526-30

45. Müller S, Seelig J. In vivo NMR imaging of deuterium. Journal of Magnetic Resonance 1987;72:456-66

46. Brereton IM, Irving MG, Field J, Doddrell DM. Preliminary studies on the potential of in vivo deuterium NMR spectroscopy. Biochem Biophys Res Commun 1986;137:579-84

47. Brereton IM, Doddrell DM, Oakenfull SM, Moss D, Irving MG. The use of in vivo 2H NMR spectroscopy to investigate the effects of obesity and diabetes mellitus upon lipid metabolism in mice. Nmr Biomed 1989;2:55-60 
48. Diraison F, Pachiaudi C, Beylot M. In vivo measurement of plasma cholesterol and fatty acid synthesis with deuterated water: Determination of the average number of deuterium atoms incorporated. Metabolism 1996;45:817-21

49. Clendening JW, Pandyra A, Boutros PC, El Ghamrasni S, Khosravi F, Trentin GA, et al. Dysregulation of the mevalonate pathway promotes transformation. P Natl Acad Sci USA 2010;107:15051-6

50. Ding $\mathrm{X}$, Zhang WH, Li S, Yang $\mathrm{H}$. The role of cholesterol metabolism in cancer. Am J Cancer Res 2019;9:219-27

51. Smith B, Land $\mathrm{H}$. Anticancer activity of the cholesterol exporter ABCA1 gene. Cell Rep 2012;2:580-90

52. Colell A, Garcia-Ruiz C, Lluis JM, Coll O, Mari M, Fernandez-Checa JC. Cholesterol impairs the adenine nucleotide translocator-mediated mitochondrial permeability transition through altered membrane fluidity. J Biol Chem 2003;278:33928-35

53. Castellano BM, Thelen AM, Moldavski O, Feltes M, van der Welle RE, Mydock-McGrane $\mathrm{L}$, et al. Lysosomal cholesterol activates mTORC1 via an SLC38A9-Niemann-Pick C1 signaling complex. Science 2017;355:1306-11

54. Huang P, Nedelcu D, Watanabe M, Jao C, Kim Y, Liu J, et al. Cellular Cholesterol Directly Activates Smoothened in Hedgehog Signaling. Cell 2016;166:1176-87 e14

55. Sheng R, Chen Y, Yung Gee H, Stec E, Melowic HR, Blatner NR, et al. Cholesterol modulates cell signaling and protein networking by specifically interacting with PDZ domain-containing scaffold proteins. Nat Commun 2012;3:1249

56. Zhuang L, Kim J, Adam RM, Solomon KR, Freeman MR. Cholesterol targeting alters lipid raft composition and cell survival in prostate cancer cells and xenografts. J Clin Invest 2005;115:959-68

57. Stopsack KH, Gerke TA, Andren O, Andersson SO, Giovannucci EL, Mucci LA, et al. Cholesterol uptake and regulation in high-grade and lethal prostate cancers. Carcinogenesis 2017;38:806-11

58. Miles JM, Wahner HW, Carpenter PC, Salassa RM, Northcutt RC. Adrenal Scintiscanning with Np-59, a New Radioiodinated Cholesterol Agent. Mayo Clin Proc 1979;54:321-7

59. Neese RA, Misell LM, Turner S, Chu A, Kim J, Cesar D, et al. Measurement in vivo of proliferation rates of slow turnover cells by $2 \mathrm{H} 2 \mathrm{O}$ labeling of the deoxyribose moiety of DNA. Proc Natl Acad Sci U S A 2002;99:15345-50

60. Burger JA, Li KW, Keating MJ, Sivina M, Amer AM, Garg N, et al. Leukemia cell proliferation and death in chronic lymphocytic leukemia patients on therapy with the BTK inhibitor ibrutinib. JCI Insight 2017;2:e89904 